\section{DETERMINATION OF FOULING MECHANISM IN ULTRAFILTRATION OF ELECTROPLATING WASTEWATER}

\author{
Danu Arionoa, Anita Kusuma Wardania, Putu Teta Prihartini Aryantib,
} Ahmad Nurul Hakima, I Gede Wentena*

aDepartment of Chemical Engineering, Institut Teknologi Bandung, Jl. Ganesha 10, Bandung 40132, Indonesia bDepartment of Chemical Engineering, Universitas Jenderal Achmad Yani, Jl. Ters. Jend. Sudirman, Cimahi 40285, Indonesia
Article history

Received

20 October 2017

Received in revised form

29 December 2017

Accepted

1 March 2018

Published online

10 May 2018

*Corresponding author igw@che.itb.ac.id

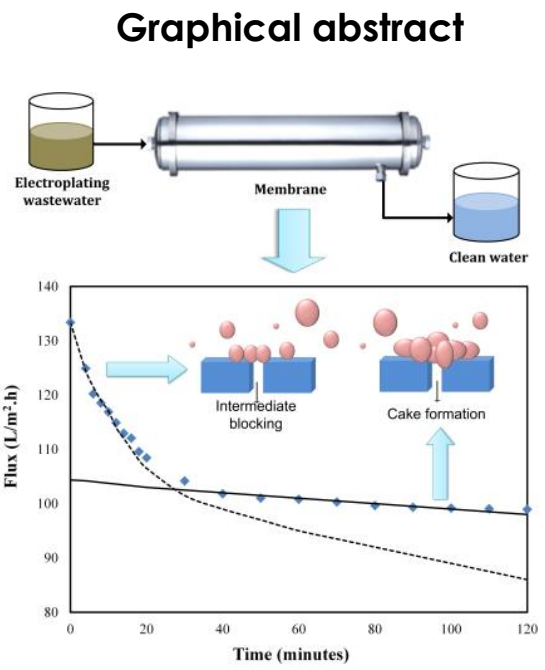

\begin{abstract}
Wastewater from electroplating industries is usually contaminated with high concentration of hazardous materials, such as nickel, copper, and chromium. Therefore, the electroplating wastewater is one of the environmental problems that require a novel solution to reduce risks for human and environment. Ultrafiltration is a promising technology to overcome this problem due to its ability to reject al suspended solids. However, membrane fouling still becomes a major obstacle in ultrafiltration processes. Fouling reduces the permeate flux and increases membrane operational costs due to membrane cleaning. In this work, fouling mechanism that occurred in polyacrylonitrile based ultrafiltration for electroplating wastewater treatment was investigated. The effects of trans-membrane pressure (TMP) and cross flow velocity on fouling mechanism were also studied. The results showed that in the first 20 minutes, intermediate blocking was occurred on the membrane surface, while cake formation was happened for the rest of filtration time. These results were applied for all TMP and cross flow velocity.
\end{abstract}

Keywords: Electroplating, fouling, nickel rejection, ultrafiltration membrane wastewater treatment

\subsection{INTRODUCTION}

Generally, wastewater from electroplating industries is contaminated with high concentration of heavy metals, such as nickel, copper, and chromium. These heavy metals are not biodegradable and tend to accumulate in living organisms, with many heavy metal ions known to be either toxic or carcinogenic [1]. Based on Minister of Environment Regulation No.9 Year 2006, Indonesian standard for nickel mine waste water is below $0.5 \mathrm{mg} / \mathrm{L}$. Meanwhile, the average nickel content in electroplating wastewater is up to $1000 \mathrm{mg} / \mathrm{L}$ [2]. Nickel concentration must be controlled to the acceptable level before being discharged to the environment, since it causes severe damage to lungs, kidneys, and gastrointestinal distress $[3,4]$.

Several technologies for treating electroplating wastewater have been recently developed to decrease the amount of nickel and improve the quality of the treated effluent, such as chemical precipitation [4], adsorption [5, 6], ion exchange [7], and membrane processes [2, 8-10]. Among those technologies, ultrafiltration (UF) membrane is one of the promising technologies to remove nickel from electroplating wastewater since UF is able to reject 
suspended solids [11-13]. UF also offers several advantages, such as high product quality, a small footprint area, and low energy consumption [14-21]. However, membrane fouling still becomes the most limitation of UF membrane. Fouling is a result of interaction between the membrane material and the components in the feed water. Fouling becomes disadvantages for ultrafiltration processes since it reduces the permeate flux and increase membrane operational costs due to membrane cleaning [14, 22].

In this work, nickel removal was conducted using polyacrylonitrile (PAN) based UF membrane. Membrane flux was measured at different transmembrane pressure (TMP) and cross flow velocity. Hermia's fouling model was used to determine dominant fouling mechanism that occurred in PAN based UF for electroplating wastewater treatment. In addition, reverse osmosis (RO) water and $\mathrm{HCl} 1 \%$ were used as backwash solution to recover the initial flux.

\subsection{METHODOLOGY}

\subsection{Materials}

Polyacrylonitrile (PAN) UF membrane with MWCO 100 $\mathrm{kDa}$ and surface area $0.0369 \mathrm{~m}^{2}$ was used in this work. Meanwhile, characteristic of the wastewater is shown in Table 1.

Table 1 Wastewater characteristic

\begin{tabular}{|c|c|}
\hline Parameter & Concentration \\
\hline $\mathrm{Ni}$ & $381.6 \mathrm{ppm}$ \\
\hline $\mathrm{TDS}$ & $241.6 \mathrm{ppm}$ \\
\hline $\mathrm{pH}$ & 5.1 \\
\hline
\end{tabular}

Furthermore, $\mathrm{RO}$ water and $\mathrm{HCl} 1 \%$ solution were used for membrane backwashing to restore the initial flux. Backwash was conducted by circulating the backwash solution to permeate site.

\subsection{Filtration Process}

UF membrane filtration was carried out at different pressure $(0.6,1$, and 2 bar) and cross flow velocity $(0.46,1.02$, and $1.18 \mathrm{~m} / \mathrm{s})$. Schematic illustration of the UF system is shown in Figure 1. Flux was measured every five minutes operation time until stable flux was attained. Sample of permeate was taken to check nickel content after membrane operation.

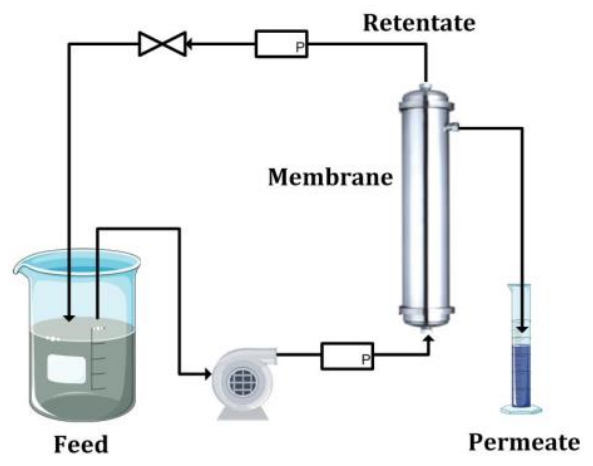

Figure 1 Schematic illustration of the UF system

\subsection{Modeling of Membrane Fouling}

In general, there are four fouling mechanism, i.e. complete blocking, intermediate blocking, standard blocking, and cake formation. In complete blocking and intermediate blocking, the particles have the same size with membrane pores, thus the particles seal off pore entrances and prevent flow. However, for intermediate blocking, there is accumulation of some particles on top of other deposited particles. This accumulation is not occurred in complete blocking. Meanwhile, standard blocking is essentially results in a decrease of the membrane porosity and increase of membrane resistance since the bulk phase particles are small enough to enter the membrane pores [23]. The particles are accumulated inside membranes on the walls of cylindrical pores, thus the pores become constricted and the permeability of the membrane is reduced. Furthermore, cake formation occurs when bigger particles accumulate on the surface of a membrane in a permeable cake of increasing thickness that increases membrane resistance.

In this work, fouling mechanism based on the experiment data was determined by considering the flux expressions relative to the fouling mechanisms, which was established by Hermia [24]. Hermia proposed a mathematical model describing fouling mechanisms as stated in equation (1).

$$
\frac{d^{2} t}{d V^{2}}=k\left(\frac{d t}{d V}\right)^{m}
$$

where $t$ is the filtration time and $V$ is the total filtered volume. $m$ denotes a parameter of cake formation, standard blocking, intermediate blocking, and complete blocking respectively, each of which has values of $0,3 / 2,1$, and 2 . Meanwhile, the value of $k$ represents fouling parameter, which varied for each UF processes.

Meanwhile, flux of UF membrane can be defined by equation (2) [11].

$$
I=\frac{1}{A} \frac{d V}{d t}
$$


where $A$ is membrane area and $J$ is permeate flux. By combining equation (1) and (2), the flux decline can be expressed as a new equation below.

$$
\frac{d J}{d t}=-k J(A)^{2-m}
$$

Furthermore, the equation characterizing of flow decline due to fouling is detailed in Table 2.

Table 2 Flux equation for each fouling mechanism

\begin{tabular}{|c|c|c|}
\hline Fouling mechanism & Flux equation & Eq. \\
\hline $\begin{array}{l}\text { Cake formation } \\
m=0\end{array}$ & 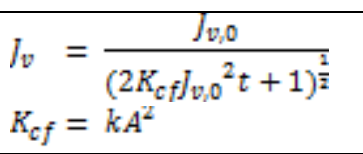 & (4) \\
\hline $\begin{array}{l}\text { Standard blocking } \\
m=3 / 2\end{array}$ & $\begin{array}{l}I_{v}=\frac{4 J_{y, 0}}{\left(2 K_{B b} J_{b y 0^{2 / 2}} t+2\right)^{2}} \\
K_{g b}=k A^{1 / 2}\end{array}$ & (5) \\
\hline $\begin{array}{l}\text { Intermediate } \\
\text { blocking } \\
m=1\end{array}$ & $\begin{array}{l}J_{v}=\frac{J_{w 0}}{K_{i b} J_{n: 0} t+1} \\
K_{i b}=k A\end{array}$ & (6) \\
\hline $\begin{array}{l}\text { Complete blocking } \\
m=2\end{array}$ & $\begin{array}{l}l_{v}=J_{5,0} \exp \left(-K_{a b} t\right) \\
K_{c b}=k\end{array}$ & (7) \\
\hline
\end{tabular}

\subsection{RESULTS AND DISCUSSION}

\subsection{The Effect of Trans Membrane Pressure and Cross} Flow Velocity

In this work, TMP was varied at 0.56, 1, and 2 bar. Meanwhile, permeate flux was measured every five minutes operation time until stable flux was attained. The effect of TMP on the permeate flux is presented in Figure 2. The results showed that flux was increased with the increase of TMP. Theoretically, when TMP is too low, it will be difficult to push the feed through the membrane pores. Therefore, most of the feed solution are drifted to the retentate [15].

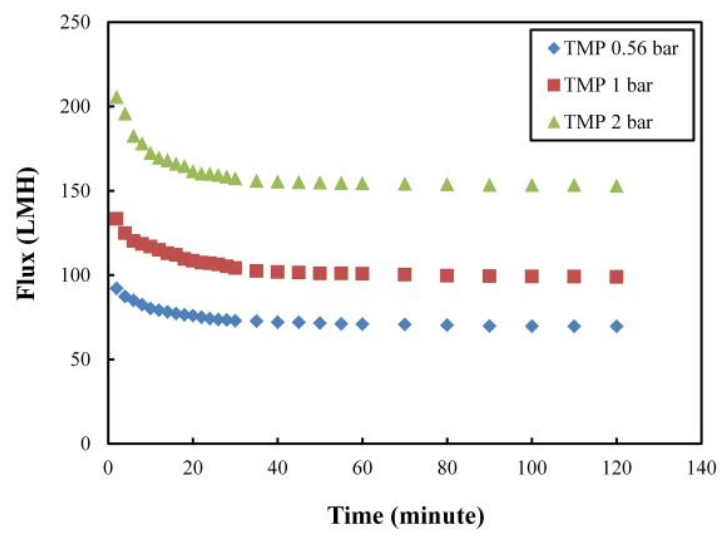

Figure 2 The effect of TMP on the permeate flux at contant cross flow velocity $1.18 \mathrm{~m} / \mathrm{s}$
The effect of TMP on the nickel rejection is shown in Figure 3. The nickel rejection was calculated by equation (8).

$$
R(\%)=\frac{c_{f}-c_{p}}{c_{f}} \times 100 \%
$$

where $R$ is nickel rejection, $C_{f}$ is nickel concentration in feed and $C_{p}$ is nickel concentration in permeate. From Figure 3, it can be seen that the higher nickel rejection was obtained at TMP 1 bar.

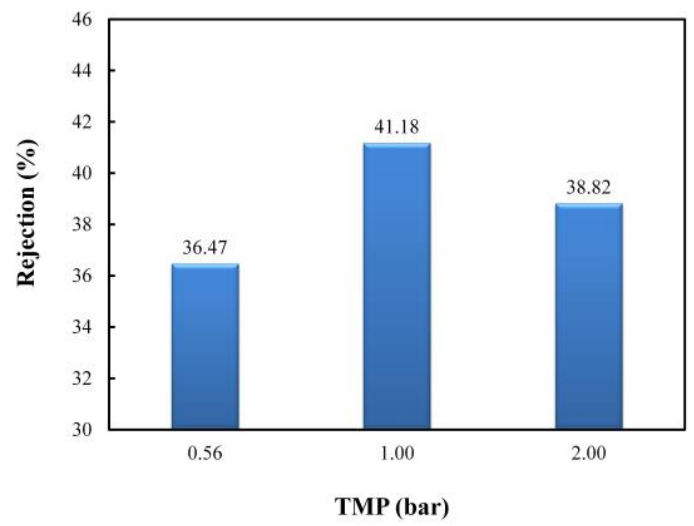

Figure 3 The effect of TMP on the nickel rejection at contant cross flow velocity $1.18 \mathrm{~m} / \mathrm{s}$

Permeate flux in UF process not only depends on the TMP, but also on the cross flow velocity. In this work, the effect of cross flow velocity to the membrane flux was also studied. The cross flow velocity of the UF was varied from 0.46 to $1.18 \mathrm{~m} / \mathrm{s}$ with a constant TMP of 1 bar. The results showed that the increase of cross flow led to the increase of permeate flux, as shown in Figure 4.

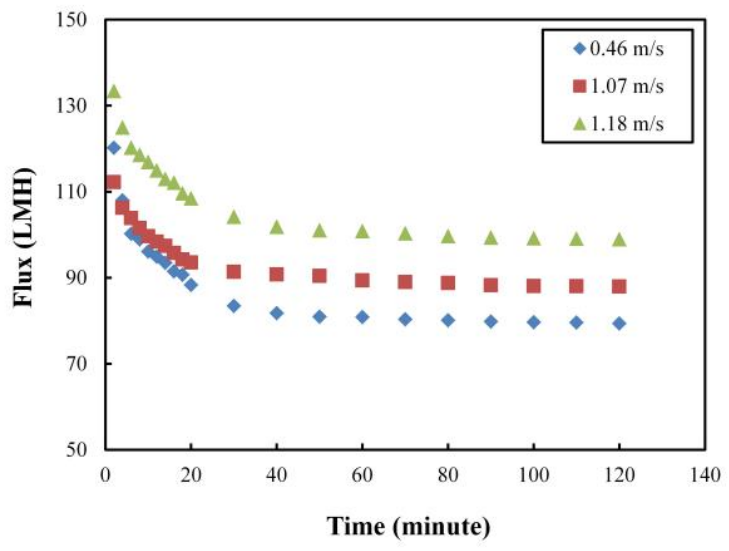

Figure 4 The effect of cross flow velocity to the permeate flux at constant TMP 1 bar 


\subsection{Determination of Fouling Mechanism}

To determine the fouling mechanism of ultrafiltration process in this work, the optimization of fouling parameters $\left(K_{c f}, K_{s b}, K_{i b}\right.$, and $\left.K_{c b}\right)$ was done by the least squares method programmed with Matlab
R2015b. Two steps of calculations are implemented to find the fouling mechanisms on the PAN based UF membrane.

Table 3 Fouling parameter for each mechanism

\begin{tabular}{cccccc}
\hline TMP (bar) & Cross flow velocity $(\mathrm{m} / \mathbf{s})$ & $K_{c f}$ & $K_{\text {sb }}$ & $K_{\text {ib }}$ & $K_{c b}$ \\
\hline 0.56 & 1.18 & $4.29 \times 10^{-7}$ & $5.18 \times 10^{-4}$ & $5.67 \times 10^{-5}$ & $4.60 \times 10^{-3}$ \\
\hline 1 & 1.18 & $3.03 \times 10^{-7}$ & $3.75 \times 10^{-4}$ & $3.62 \times 10^{-5}$ & $3.90 \times 10^{-3}$ \\
\hline 2 & 1.18 & $2.73 \times 10^{-7}$ & $1.95 \times 10^{-4}$ & $2.04 \times 10^{-5}$ & $2.90 \times 10^{-3}$ \\
\hline 1 & 0.46 & $5.86 \times 10^{-7}$ & $6.16 \times 10^{-4}$ & $6.63 \times 10^{-5}$ & $5.70 \times 10^{-3}$ \\
\hline 1 & 1.07 & $3.29 \times 10^{-7}$ & $3.22 \times 10^{-4}$ & $3.32 \times 10^{-5}$ & $3.10 \times 10^{-3}$ \\
\hline
\end{tabular}

For the first-time period or the first phase, Jo was fixed to the first experimental flux data corresponding to initial time to. Meanwhile, for the second phase, the value of Jo was considered as the last flux value of the first fouling phase. The values of fouling parameters are presented in Table 3.

Figure 5 shows that up to $20 \%$ of flux decline was occurred in the first stage of filtration time 11-20 minutes), while the flux decline was around $8 \%$ in the second stage (20-120 minutes). In the first 20 minutes, the small particles are attached on the UF membrane surface and cause intermediate pore blocking, thus some of the membrane pores are covered by a fraction of foulant. The foulant deposited on the membrane surface not only contribute to pore blocking but also attach to other foulant on the membrane surface. Furthermore, after 20 minutes of filtration a cake layer is formed. In this second phase, it is difficult for feed solution to penetrate through membrane since most of the pores have been completely blocked. These results were applied for all TMP and cross flow velocity.

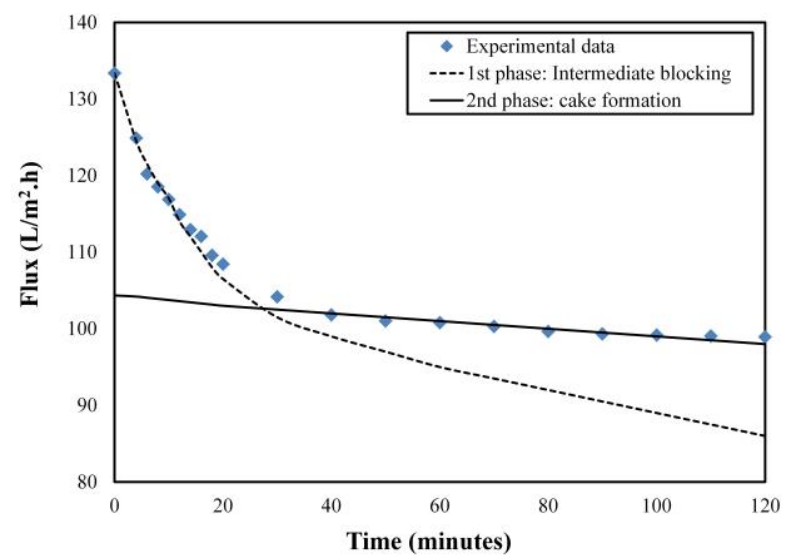

Figure 5 Comparison of experimental data and simulation of fouling mechanism on PAN based UF membrane at TMP 1 bar and cross flow velocity $1.18 \mathrm{~m} / \mathrm{s}$

\subsection{The Effect of Backwash}

After operated within a certain time, permeate flux is usually decreased due to membrane fouling. Therefore, backwash is needed to restore the flux, although it cannot reach the same value of the initial flux. In this work, $\mathrm{RO}$ water and $\mathrm{HCl} 1 \%$ were used as backwash solution. The effect of TMP and backwash solution to the flux recovery is presented in Table 4.

Table 4 The effect of backwash solution to flux recovery

\begin{tabular}{ccc}
\hline \multirow{2}{*}{ TMP } & \multicolumn{2}{c}{ Flux recovery (\%) } \\
\cline { 2 - 3 } & RO water & HCl 1\% \\
\hline 0.56 & 56.40 & 61.10 \\
\hline 1.00 & 65.30 & 70.10 \\
\hline 2.00 & 70.20 & 70.20 \\
\hline
\end{tabular}

By using RO water, flux recovery of $56.40 \%, 65.30 \%$, and $70.20 \%$ could be achieved for TMP $0.56,1$, and 2 bar, respectively. Furthermore, backwash by circulating $\mathrm{HCl}$ solution could achieve higher flux recovery for TMP 0.56 and 1 bar. Meanwhile, for TMP 2 bar, the flux recovery for both solutions is $70.20 \%$.

\subsection{CONCLUSION}

In this work, PAN based UF membrane was used to remove nickel from electroplating wastewater. Membrane flux was measured at different TMP and cross flow velocity. The results showed that the permeate flux was increased with the increase of TMP and cross flow velocity. Furthermore, in the first 20 minutes, intermediate blocking was occurred on the membrane surface, while cake formation was happened for the rest of filtration time. These results were applied for all TMP and cross flow velocity. In addition, the use of $\mathrm{RO}$ water and $\mathrm{HCl}$ solution in 
backwash process could recover the initial flux up to $70 \%$.

\section{References}

[1] Li, Z. et al. 2014. A Review of Soil Heavy Metal Pollution From Mines in China: Pollution and Health Risk Assessment. Science of The Total Environment. 468(Supplement C): 843-853.

[2] Dermentzis, K. 2010. Removal of Nickel from Electroplating Rinse Waters Using Electrostatic Shielding Electrodialysis/Electrodeionization. Journal of Hazardous Materials. 173(1-3): 647-652.

[3] Axtell, N. R. et al. 2003. Lead and Nickel Removal Using Microspora and Lemna Minor. Bioresource Technology. 89(1): 41-48.

[4] Wardani, A. K. et al. 2017. Study on the Influence of Applied Voltage and Feed Concentration on the Performance of Electrodeionization in Nickel Recovery from Electroplating Wastewater. AIP Conference Proceedings. 1805(1): 030004

[5] Martín-Lara, M. A. et al. 2014. New Treatment of Real Electroplating Wastewater Containing Heavy Metal Ions by Adsorption onto Olive Stone. Journal of Cleaner Production. 81 (Supplement C): 120-129.

[6] Vocciante, M. et al. 2014. A Rigorous Procedure for the Design of Adsorption Units for the Removal of Cadmium and Nickel from Process Wastewaters. Journal of Cleaner Production. 77(Supplement C): 35-46.

[7] Alyüz, B. dan S. Veli, 2009. Kinetics and Equilibrium Studies for the Removal of Nickel and Zinc from Aqueous Solutions by Ion Exchange Resins. Journal of Hazardous Materials. 167(1): 482-488.

[8] Tasser, C. dan F. P. Reinhard. 2003. Recovery of Nickel and Chromium (111) with Advanced Electrodelonization. Metal Finishing. 101 (11): 28-29.

[9] Shang, G. H. et al. 2014. Treatment of Dilute Ni2+Containing Wastewater by Electrodeionization with Bipolar Membrane: Precipitation. Zhongguo Youse Jinshu Xuebao/Chinese Journal of Nonferrous Metals. 24(10): 2684-2691.

[10] Ariono, D. et al. 2017. Heterogeneous Structure and Its Effect on Properties and Electrochemical Behavior of Ion- exchange Membrane. Materials Research Express. 4(2): 024006.

[11] Cho, J. et al. 2000. Membrane Filtration of Natural Organic Matter: Factors and Mechanisms Affecting Rejection and Flux Decline with Charged Ultrafiltration (UF) Membrane. Journal of Membrane Science. 164(1-2): 89-1 10.

[12] Aoustin, E. et al. 2001. Ultrafiltration of Natural Organic Matter. Separation and Purification Technology. 22-23: 6378.

[13] Lowe, J. dan M. M. Hossain. 2008. Application of Ultrafiltration Membranes for Removal of Humic Acid from Drinking Water. Desalination. 218(1): 343-354.

[14] Aryanti, P. et al. 2016. The Influence of PEG400 and Acetone on Polysulfone Membrane Morphology and Fouling Behaviour. Journal of Engineering and Technological Sciences. 48(2): 135-149.

[15] Wardani, A. K. et al. 2017. Combined UltrafiltrationElectrodeionization Technique for Production of High Purity Water. Water Science and Technology. 75(12): 2891-2899.

[16] Shi, X. et al. 2014. Fouling and Cleaning of Ultrafiltration Membranes: A Review. Journal of Water Process Engineering. 1: 121-138.

[17] Aryanti, P. et al. 2017. Modified Membrane with Antibacterial Properties. Membrane Water Treatment. 8(5): 463-481.

[18] Sianipar, M. et al. 2017. Functionalized Carbon Nanotube (CNT) Membrane: Progress and Challenges. RSC Advances. 7(81): 51175-51198.

[19] Wenten, I. G. et al. 2017. Chapter 11 - The Bubble Gas Transport Method. Membrane Characterization. Elsevier. 199-218.

[20] Desiriani, R. et al. 2017. Membrane-Based Downstream Processing of Microbial Xylitol Production. Chemical Engineering. 8(8)

[21] Himma, N. F. et al. 2017. The Effects of Non-solvent on Surface Morphology and Hydrophobicity of Dip-Coated Polypropylene Membrane. Materials Research Express. 4(5): 054001

[22] Ariono, D. et al. 2017. The effect of Polymer Concentration on Flux Stability of Polysulfone Membrane. AIP Conference Proceedings. 1788(1): 030048.

[23] Broeckmann, A. et al. 2006. Modeling of Pore Blocking and Cake Layer Formation in Membrane Filtration for Wastewater Treatment. Desalination. 189(1): 97-109.

[24] Hermia, J. 1982. Constant Pressure Blocking Filtration Law Application to Powder-Law Non-Newtonian Fluid. Trans. Inst. Chem. Eng. 60: 183-187. 